\title{
The Systematic Review of Web Measurement
}

\author{
Dr.Arvinder Kaur $^{1}$ and Diksha Dani ${ }^{2}$ \\ ${ }^{1}$ Guru Gobind Singh Inderprastha University,New Delhi,India \\ arvinderkaurtakkar@yahoo.com \\ ${ }^{2}$ Inderprastha Engineering College, Ghaziabad,India \\ dikshadani@yahoo.com
}

\begin{abstract}
This paper provides a systematic review of previous web measurement studies particularly focussing on web quality, web metric, models and methods.The paper reviews journals and conference proceedings to evaluate the progress and direct future research in this area.
\end{abstract}

\section{Keywords:}

web metrics, web measurement, web quality, web quality models

\section{Introduction}

The science of web measurement tries to measure the different attributes of web to gain knowledge of it in order to optimize it and improve its capacity for delivering information more effectively. Web measurement is the collection, analysis and reporting of internet data for purposes of understanding and optimizing web usage. Effective Web measurement is more than looking at a few page hit numbers.

According to Björneborn et al, the definition of webometrics is "the study of the quantitative aspects of the construction and use of information resources, structures and technologies on the Web drawing on bibliometric and infometric approaches"[2]. A second definition of webometrics has also been introduced, "the study of web-based content with primarily quantitative methods for social science research goals using techniques that are not specific to one field of study[3], which emphasizes a small subset of relatively applied methods for use in the wider social sciences. A website is a collection of web pages, images, videos that are hosted on a Web server, usually accessible using the Internet . Web metrics is concerned with measuring and quantifying different attributes of the web: web sites, web pages, parts of web pages, words in web pages, hyperlinks, web search engine results. The web has become important communication medium and provide wide range of information on almost all possible topic and area.

These huge and easily accessible source of information, has provided vast possibilities of measurement on a large scale (e.g., the number of web sites, the number of web pages, the number of blogs, number of links) or on a smaller scale (e.g., the number of web sites in a country, the number of web pages in a web site etc).

\section{Research method}

This systematic review aims at summarizing the existing research in the area of web measurement and identify any gaps in the past research to suggest areas of further research in web quality evaluation. The review does not describe method or procedure or metric in detail.

DOI : $10.5121 /$ ijcses.2011.2305 


\subsection{Research questions}

The research questions stem from need to find out what research work can be undertaken in the area of web measurement. To achieve this we adopted systematic review method that would answer the following research questions. The questions are:

RQ1: Which quality models have been suggested so far?

RQ2: What research has been done in the area of web quality evaluation?.

RQ3: Which quality factors for web measurement in the literature have been evaluated empirically?

RQ4:What are the implication of these studies for software industry and research community?

It was found that asking these questions were essential not only for deciding what should be the content and structure, but also for guiding the review process including strategies for locating and selecting studies, for critically appraising the studies, and for analysing their results. The literature that informed the study originated from a variety of sources, including both qualitative, quantitative, and mixed methods research. To achieve our objective ,the systematic review was done in accordance to the guideline proposed by Kitchenham et al.

\subsection{Identification of research}

\subsubsection{Search Criteria}

A comprehensive, unbiased search is one of the fundamental factors that distinguish a SR from a traditional literature review. A systematic search begins with the identification of keywords and search terms which are appropriate for answering the question to the research answers. The initial search criteria were broad in order to include articles with different uses of terminology. The key words that were found to be most appropriate were <web metrics $>$, <web measurement $>$, <web analytics $>,<$ web engineering $>$, <website quality $>$. These search terms may be combined with $<$ and $><$ or $>$ search operators. The start year was set to 1990 to ensure that most relevant research within the field would be included, and the last date for inclusion is publications within 2010 .

\subsubsection{Search Process and study selection}

The search process comprised two phases: primary search and secondary search.

The following types of paper were included:

- Paper presenting and evaluating web quality metrics

- Paper proposing and evaluating approaches of web quality.

- Papers proposing framework, methods or models of web quality.

\subsubsection{Primary search process and study selection.}

The primary search process was directed towards searching online databases, search engines, electronic journals, conference proceedings, using the derived search string and issue by issue basis. The resources used were chosen because the literature contained publications that were relevant to our areas of interest. In the initial phase the papers were downloaded based on the titles that were thought relevant particularly to the web measurement and quality area. 


\subsubsection{Secondary search process and study selection.}

In the next phase the article that were downloaded in the previous phase were selected for primary studies based on their abstract. Also the references of the selected paper were reviewed to find out other major conferences and journals of the area and to find any important articles that may have been be left.

\subsubsection{Sources of information}

The following databases were covered:

ACM Digital Library (<portal.acm.org $>$ ).

ACM Transaction on Software engineering

ACM Transaction on Information System

ACM Transaction on Web

ACM Computing Surveys

ACM Transaction on Internet Technology

ACM International conference on World Wide Web

ACM International cross disciplinary conference on web accessibility(W4A)

ACM International conference on Human Factors in Computing Systems(SIGCHI)

ACM International conference on Hypertext and Hypermedia

ACM International conference om Measurement and Modelling of computer systems(SIGMETRICS)

IEEE eXplore (<ieeexplore.ieee.org >).

IEEE Multimedia

IEEE Transaction on software engineering

IEEE International conference on Quality Software

IEEE International symposium on software Metrics(METRICS)

IEEE International symposium on website Evolution

Elsevier

Journal of System and Software

Springer

Software quality Journal

Empirical Software Engineering Journal

Also following conferences were also searched:

Internet Conference on Web Engineering

International Journal on Web Engineering Technology

Museum and the Web conference

\begin{tabular}{|c|c|}
\hline $\begin{array}{c}\text { ACM Transaction of software } \\
\text { engineering and Methodology }\end{array}$ & 0 \\
\hline ACM Transaction of Information system & 2 \\
\hline ACM Transaction on Web & 0 \\
\hline ACM Computing Surveys & 02 \\
\hline $\begin{array}{c}\text { ACM Transaction of Internet } \\
\text { Technology }\end{array}$ & 07 \\
\hline ACM International conference on World & 14 \\
\hline
\end{tabular}




\begin{tabular}{|c|c|}
\hline Wide Web & \\
\hline $\begin{array}{c}\text { ACM International cross deciplinary } \\
\text { conference on web Accessibility(W4A) }\end{array}$ & 05 \\
\hline $\begin{array}{c}\text { ACM International conference on } \\
\text { Hypertext and Hypermedia }\end{array}$ & 03 \\
\hline $\begin{array}{c}\text { ACM International conference on } \\
\text { Human Factors in Computing } \\
\text { Systems(SIGCHI) }\end{array}$ & 06 \\
\hline $\begin{array}{c}\text { IEEE Transaction of Software } \\
\text { Engineering }\end{array}$ & 01 \\
\hline IEEE Multimedia & 05 \\
\hline $\begin{array}{c}\text { International Conference on Web } \\
\text { Engineering(ICWE) }\end{array}$ & 05 \\
\hline Journal on Web Engineering & 01 \\
\hline $\begin{array}{c}\text { International Journal on Web } \\
\text { Engineering and Technology }\end{array}$ & 01 \\
\hline $\begin{array}{c}\text { IEEE International Symposium on } \\
\text { website Evolution }\end{array}$ & 02 \\
\hline $\begin{array}{c}\text { IEEE International conference on } \\
\text { Quality Software }\end{array}$ & 01 \\
\hline $\begin{array}{c}\text { IEEE International symposium on } \\
\text { software Metrics }\end{array}$ & 01 \\
\hline $\begin{array}{c}\text { Software quality Journal(springer) } \\
\text { Journal of System and } \\
\text { Software(Elsevier) }\end{array}$ & 0 \\
\hline Museum and the Web Conference & 1 \\
\hline
\end{tabular}

Table 1 : Publication included in the review

\subsubsection{Threats to validity}

The main validity threat of this study are publication selection bias and misclassification. Though we have tried to search through the journal and conference on issue by issue basis but still there are chances that some paper may be missed. Some relevant sources of data were not employed because of the inaccessibility to those journals.

\section{Literature review}

Web technologies and applications are becoming increasingly important in the information systems world. One of the main problems of web developments is their short span of window owing to the ever changing world, which can result in a lack of quality. A good mechanism for controlling the quality of a web based applications (and hence of a web site) is the use of web metrics.

It is important to measure the attributes of the software quantitatively and qualitatively for understanding and enhancing it. The first step of any measurement is to define the attributes of measurement. There are number of quality attributes defined by different researchers for analysis [1].In one of the earliest studies of global measurements about the Web presented 
some difficult qualitative questions concerning the Web such as the size of the Web, its connectivity, visibility of sites and the distribution of formats, and attempts to provide some partial quantitative answers to them. It uses the numbers in these answers to drive some 3-D visualizations of localities in the $\mathrm{Web}[5]$.

\subsection{Classification of Web Measurement}

Due to the exponential growth of the Web, we require new metrics that may provide deeper insight on the Web as a whole and also on individual sites from different perspectives. One of the most important motivation for deriving such metrics is their contribution in improving the quality of information available on the Web. The paper by Dhyani et al [6] presented the origins, measurement functions, formulations and comparisons of well known Web metrics for quantifying :

(a) Web graph properties: The World Wide Web can be represented as a graph structure where web pages comprise nodes and hyperlinks denote directed edges. Graph-based metrics quantify structural properties of the Web on both macroscopic and microscopic scales.

(b) web page significance: Significance metrics formalize the notions of "quality" and "relevance" of web pages with respect to information needs of users.

(c) web page similarity: Similarity metrics quantify the extent of relatedness between web pages.

(d) search and retrieval: These are metrics for evaluating and comparing the performance of Web search and retrieval services.

(e) usage characterization: Patterns and regularities in the way users browse Web resources can provide invaluable clues for improving the content, organization and presentation of web sites. and (f) information theoretic properties: Information theoretic metrics capture properties related to information needs, production and consumption. It also discussed how these metrics can be applied for improving Web information access and use. It is perhaps the only extensive survey on web metrics.

The paper by Kleinberg et al[8] has discussed web as a graph with reasons for studying the web graph like improved web search. In another study, Mendes et al[7], metrics were organized into five categories:

(1) length size

(2) reusability

(3) complexity size

(4) effort and

(5) confounding factors.

In this paper we have categorized the research papers according to different quality models proposed and different quality attributes that have been evaluated .

\subsubsection{Web quality Models}

Literature shows that measurement of the quality attributes of web based applications is a difficult task due to the dynamic nature of environment in which it is deployed and used in a variety of organizational and industrial contexts . 
A web application is a complex heterogeneous system which involves many subsystems, applications, languages and databases. It is difficult identify and define the common attributes for the quality model that may be applicable in evaluation of quality of wide range of web applications or web sites. Another problem in designing the web quality model is that the designer has no control on the devices and applications that the user is going to use when accessing the website. This requires additional effort in determining questions and metrics that cover all the possibilities.

Mich et al presents general purpose approach to evaluate a web site that provides guidelines for website design and a framework for analysis and evaluation of websites independently of their goals and domains[9]. The 2QCV3Q, also called 7-loci, is a conceptual model to evaluate web site quality based on seven dimensions: who-what-why-when-where how, and feasibility (with what means and devices). The 2QCV3Q model takes its name from the initials of the Ciceronian loci on which it is based, namely: Quis (Identity), Quid (Content), Cur (Services), Ubi (Location), Quando (Management), Quomodo (Usability), Quibus Auxiliis (Feasability). A usability-focused evaluation method for hypermedia application is MiLE, based on a combination of inspection from expert evaluator and empirical testing through panels of end users[10]. The evaluation model here is based on two heuristic concepts: abstract and concrete tasks Another comprehensive quality model aimed at defining a quality model that considered five dimensions namely correctness, presentation, content, navigation and interaction [12].

A three dimensional web quality mode WQM defined a cube structure in which three aspect were considered that must be taken into account in the evaluation of websites. They were features, quality characteristics, and life cycle processes. Each dimension must be considered as a hierarchical structure, composed by other more basic elements[13].

The Web QEM model presents a methodology that may be useful in systematically assess 4 model presents a methodology that may be useful in systematically assess characteristics, sub characteristics and attributes that influence the product quality in operative as well as early phase of web development project in diverse application domains.[14]

A paper by Andreou et al proposed an efficient web application quality evaluation model [WAQE] that is based on two axioms: internal (within the organisation) and external (the users). The model places emphasis on quality issues as defined by ISO 9126 and other web quality factors and utilizes importance-based criteria for evaluating requirements[15].

In recent work, the researchers proposed a new quality evaluation model Web Q-Model for websites that is intuitive, scalable and work to apply, facilitating developers and designers' work and the dialogue among them and the managers.It classifies the attributes into three Qlevels namely basic ,normal and exciting to differentiate the attributes on the basis of their importance and essentiality, which will enable the managers to propose different quality approaches to work their customers, corresponding to different prices, times and resources to employ[16].

\begin{tabular}{|c|c|c|}
\hline Model & Publication & Year(Ref) \\
\hline $\begin{array}{l}\text { 2QCV3Q } \\
\text { Loci)[ }\end{array}$ & $\begin{array}{l}\text { IEEE } \\
\text { Multimedia }\end{array}$ & 2003(9) \\
\hline $\begin{array}{l}\text { Comprehensive } \\
\text { model for } \\
\text { website }\end{array}$ & $\begin{array}{l}\text { IEEE } \quad \text { (WSE } \\
2005)\end{array}$ & $2005(12)$ \\
\hline QEM & ICSE & 2001(11) \\
\hline
\end{tabular}




\begin{tabular}{|l|l|l|}
\hline & $\begin{array}{l}\text { 99,Springer } \\
\text { LNCS }\end{array}$ & \\
\hline Web QEM & $\begin{array}{l}\text { IEEE } \\
\text { Multimedia }\end{array}$ & 2002(14) \\
\hline Web-QModel & $\begin{array}{l}\text { ACM(CHI } \\
\text { 2008) }\end{array}$ & 2008(16) \\
\hline MiLE & $\begin{array}{l}\text { Mueums and the } \\
\text { Web 2002 } \\
\text { Proceeding }\end{array}$ & 2002(10) \\
\hline WAQE & $\begin{array}{l}\text { International } \\
\text { Journal of web } \\
\text { engineering and } \\
\text { technology }\end{array}$ & $2007(15)$ \\
\hline $\begin{array}{l}\text { A Three } \\
\text { Dimensional } \\
\text { Web Quality } \\
\text { Model }\end{array}$ & $\begin{array}{l}\text { ICWE(Springer) } \\
\text { Todel }\end{array}$ & \\
\hline
\end{tabular}

Table2: Web Quality Models from the review

\subsubsection{Quality perspective}

The website can be evaluated from different perspective. There are various aspects of web that can be measured to get the indication of website quality. Web metrics provides the basis of improving the website quality. In recent years, several experts have worked on different proposals to improve web quality, including methodologies, quality frameworks, estimation models, usability guidelines, assessment methods, and metrics. The design of web application has direct influence on the quality and efficiency of web. In fact, web metrics is a particularly valuable area of ongoing, commercially relevant research.In this paper we focus on quality aspects like web navigability, web usability, web search and retrieval, web accessibility and web metrics.

\subsubsection{Web Navigability}

All web applications are made up of a set of pages. Navigation is one of the most important aspects of a web design. Therefore one of the primary concerns of a web application is to manage the navigation between these pages . User's web behavior is unpredictable. The user's eye scans across a page to decide what link to click on. So it is necessary to study and track the user navigation behavior in order to predict the next page accesses. There are various web navigation modeling approaches for web application that have been found in the literature. The problem of modeling and predicting a user's browsing behavior on a Web site has been addressed by many researchers by different approaches

Web graph properties reflect the structural organization of hypertext. The study of web as a graph is studied by number of researchers[23]. Z. Ding et al. proposed a formal model to 
specify web navigation[34]. Yuming Zhou et al proposed a navigability measure using Markov Model.[42]. Hypermedia documents can be seen as a collection of interconnected pages. User navigation can be seen as an overlay of the site graph, consisting of only the pages visited and the links followed - the navigation graph. This navigation graph can contain information about one user. Attributes can be assigned to the pages and links within both the site graph and the navigation graph[17].

A hyperlink is a structural unit that connects two Web pages . Evaluation of the link structure of a web site and its redefinition increase efficiency. The hyperlink analysis can be used for a wide variety of purposes, ranging from ranking pages returned from a web search engine to understanding the social dynamics behind the usage of the Web as a whole. A novel website link structure evaluation and improvement method based on User Visiting Patterns by optimizing and re-evaluating the link structure to increase Average Connectivity is proposed by Baoyao Zhou et al[57].

Wen-Kui Chang proposed a framework for evaluation of Web site's navigational structure to enhance Web quality using the principle of statistical usage testing to develop an efficient and effective testing mechanism[45].

The hyperlink analysis is important also because the users are more often lost in complex cross linking hypertext structures.There have been a number of algorithms proposed for analyzing hypertext link structure like page rank algorithm[29], SALSA[30], Web Page Reputations[31], Hub-Averaging-Kleinberg algorithm[37]. The paper[18] suggest one way to analyze the structure of a hypertext by identifying hierarchies and metrics. The metrics suggested were compactness, stratum, depth and imbalance. The collection of techniques provides different dimensions of the hypertext, which should allow designers to reduce undesired structural complexity and create documents that readers can traverse more easily. Probabilistic Link Prediction and Path Analysis using Markov Chains or model is proposed and evaluated in $[22,24,56]$. Angle et al proposed method for Hyperlinks Analysis of Dynamic Web Applications[33]. Eleni et al in their paper proposed techniques and metrics for improving website structure and evaluated the proposed algorithm with real world data..[34].

The studies in web navigation model for blind people is also reported in many papers [47].

\subsubsection{Web Usability}

Usability is a primary motivating factor in any development. Web application is no different usability is the measure of ease or difficulty that users experience with the system. Several studies for comparing usability for web development have been reported in the literature[32]. Th paper[32] presented the evaluation of seven methods and tools for the measurement of usability in software products and software artifacts in the web.

Rui Lopes et al presented a theoretical model to study the universal usability of the Web, i.e., how usable websites are to a wide range of audiences. The authors defined a set of universal usability metrics (UUM) to be applied into Web portions at different abstraction level[59]. Ed It. Chi et al proposed an architecture for analysis of website usability[53].

Usability evaluation techniques include Heuristic Evaluation [63],Cognitive Walkthrough for the Web (CWW)[54], in which CWW is particularly used in the design and usability 
evaluation of websites. Perhaps the study by M. Y. Ivory and M. A. Hearst [60] is the most extensive survey for automated usability evaluation methods based on new taxonomy.

Studies of correlations among usability aspects are also reported in some papers[55]

\subsubsection{Web Accessibility}

Predicting a user's behavior on a Web site for web accesses is discussed in [19]. G.A. Di Lucca et al proposed a model for identification, validation and correction of accessibility violations in existing Web sites.

The issues of web accessibility for blind and disabilities is discussed in $[49,50]$.

\begin{tabular}{|c|c|c|c|c|c|}
\hline Sno. & Name of the Paper & Authors & Year & $\begin{array}{l}\text { No of } \\
\text { Citations }\end{array}$ & $\begin{array}{l}\text { Ref } \\
\text { no }\end{array}$ \\
\hline 1 & $\begin{array}{l}\text { The anatomy of a large-scale } \\
\text { hypertextual Web search } \\
\text { engine. }\end{array}$ & S. Brin and L. Page & 1998 & 2208 & 29 \\
\hline 2 & Graph structure in the web & $\begin{array}{l}\text { A. Broder, R. } \\
\text { Kumar,F. Maghoul, P. } \\
\text { Raghavan, S. } \\
\text { Rajagopalan, R Stata, } \\
\text { A. Tomkins, J. Wiener }\end{array}$ & 2000 & 1968 & 23 \\
\hline 3 & $\begin{array}{l}\text { Heuristic Evaluation Of User } \\
\text { Interfaces }\end{array}$ & $\begin{array}{l}\text { Jukob Nielsen and Rolf } \\
\text { Molich }\end{array}$ & 1990 & 1099 & 63 \\
\hline 4 & $\begin{array}{l}\text { The Web as a graph: } \\
\text { Measurements, models, and } \\
\text { methods. }\end{array}$ & $\begin{array}{l}\text { ]J.M.Kleinberg, R. } \\
\text { Kumar, P.Raghavan, } \\
\text { S. Rajagopalan, \&A. } \\
\text { Tomkins }\end{array}$ & 1999 & 645 & 8 \\
\hline 5 & $\begin{array}{l}\text { Structural Analysis of } \\
\text { Hypertexts:Identifying } \\
\text { Hierarchies and Useful } \\
\text { Metrics, }\end{array}$ & $\begin{array}{c}\text { R. A. } \\
\text { Botafogo,E.Rivlin,Ben } \\
\text { Shneiderman }\end{array}$ & 1992 & 459 & 18 \\
\hline 6 & $\begin{array}{l}\text { The State of the Art in } \\
\text { Automating Usability } \\
\text { Evaluation of User Interfaces }\end{array}$ & $\begin{array}{l}\text { M. Y. Ivory and M. A. } \\
\text { Hearst. }\end{array}$ & 2001 & 440 & 60 \\
\hline 7 & $\begin{array}{l}\text { A technique for measuring } \\
\text { the relative size and overlap } \\
\text { of public web search engines }\end{array}$ & K. Bharat, A Broder & 1998 & 365 & 39 \\
\hline 8 & $\begin{array}{l}\text { The stochastic approach for } \\
\text { link-structure analysis } \\
\text { (SALSA) and the TKC effect. }\end{array}$ & & 2000 & 365 & 30 \\
\hline 9 & $\begin{array}{l}\text { Link Prediction and Path } \\
\text { Analysis Using Markov } \\
\text { Chains. }\end{array}$ & Ramesh R. Sarukkai & 2000 & 328 & 22 \\
\hline 10 & $\begin{array}{l}\text { Selective Markov Models for } \\
\text { Predicting Web Page }\end{array}$ & $\begin{array}{l}\text { M.Deshpande, G. } \\
\text { Karypis }\end{array}$ & 2004 & 311 & 19 \\
\hline
\end{tabular}


International Journal of Computer Science \& Engineering Survey (IJCSES) Vol.2, No.3, August 2011

\begin{tabular}{|c|c|c|c|c|c|}
\hline & Accesses & & & & \\
\hline 11 & $\begin{array}{l}\text { 2000. How dynamic is the } \\
\text { web? }\end{array}$ & $\begin{array}{l}\text { B.Brewington and } \mathrm{G} \\
\text { Cybenko }\end{array}$ & 2000 & 299 & 21 \\
\hline 12 & Measuring the web & T.Bray & 1996 & 286 & 5 \\
\hline 13 & $\begin{array}{l}\text { Finding authorities and hubs } \\
\text { from link structures on the } \\
\text { world wide web }\end{array}$ & $\begin{array}{l}\text { A.Borodin, G. } \\
\text { Roberts, J. S. } \\
\text { Rosenthal and P. } \\
\text { Tsaparas }\end{array}$ & 2001 & 247 & 37 \\
\hline 14 & A survey of Web metrics & $\begin{array}{l}\text { D. Dhyani,W.K. Ng, } \\
\text { and S.S. Bhowmick }\end{array}$ & 2002 & 184 & 6 \\
\hline 15 & $\begin{array}{l}\text { Empirically Validated Web } \\
\text { Page Design Metrics }\end{array}$ & $\begin{array}{l}\text { Melody Y. } \\
\text { Ivory,Rashmi R. Sinha, } \\
\text { Marti A. Hearst }\end{array}$ & 2001 & 177 & 52 \\
\hline 16 & $\begin{array}{l}\text { Cognitive Walkthrough for } \\
\text { the Web. }\end{array}$ & $\begin{array}{l}\text { M. H. Blackmon, P. G. } \\
\text { Polson, M, Kitajima., } \\
\text { \& C. Lewis }\end{array}$ & 2002 & 141 & 54 \\
\hline 17 & $\begin{array}{l}\text { Personalizing Web Sites for } \\
\text { Mobile Users. }\end{array}$ & $\begin{array}{l}\text { C.R. Anderson, P. } \\
\text { Domingos, D.S. Weld }\end{array}$ & 2001 & 134 & \\
\hline 18 & $\begin{array}{l}\text { Measuring Web Application } \\
\text { Quality with WebQEM }\end{array}$ & L.Olsina,. G.Rossi & 2002 & 127 & 14 \\
\hline 19 & $\begin{array}{l}\text { What is this page known for? } \\
\text { Computing web page } \\
\text { reputations. }\end{array}$ & $\begin{array}{l}\text { D. Rafiei and A. } \\
\text { Mendelzon. }\end{array}$ & 2000 & 126 & 31 \\
\hline 20 & $\begin{array}{l}\text { The Scent of a Site: A } \\
\text { System for Analyzing and } \\
\text { Predicting Information Scent, } \\
\text { Usage, and Usability of a } \\
\text { Web Site. actions and the } \\
\text { Web }\end{array}$ & $\begin{array}{l}\text { Ed It. Chi, Peter Pirolli, } \\
\text { James Pitkow }\end{array}$ & 2001 & 91 & 53 \\
\hline
\end{tabular}

Table3:Top 20 most cited papers of the review

\subsubsection{Web Searching and information retrival}

In a paper by Coyle et al[62] described the Search Guide extension to a collaborative Web search system. It offered number of enhancements to the search process like considering the collective interests of a group of users, a level of personalization can be achieved, by reusing search history information to provide explanations alongside search results that explain to the user why the engine ranked each result in the position it occupies, navigation assistance may be provided within the selected page by using a visualization of the distribution of query terms within a page, and also by highlighting links within result pages that have been followed by previous users who have visited the page. generally can make the search more useful .

PicASHOW is a fully automated WWW image retrieval system that searchers for images on the web using hyperlink structure analysis[20]. Page Rank is one of the methods to determine a page's visibility, relevance or importance and authority in search engine. Important pages receive a higher PageRank and are more likely to appear at the top of the search results. A 
number of studies involving page ranking approaches and concepts are reported in various paper like[35,38].

Hotlinks reduce the expected number of steps needed to reach a leaf page from the tree root. Gerstel et al presented hotlink enhancement algorithm is discussed in many papers[40].

Ziv Bar-Yossef et el addressed the problem of measuring global quality metrics of search engines, like corpus size, index freshness, and density of duplicates in the corpus and presented two new estimators that are able to overcome the bias introduced by approximate degrees[28].

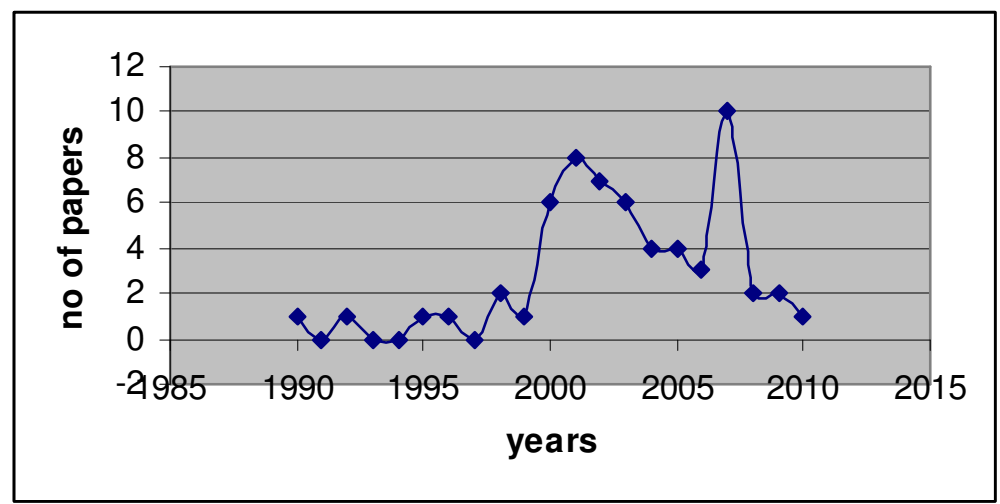

Figure $1::$ Number of papers per year in review

\subsubsection{Web Metrics}

Due to dynamic nature of web ,web pages continue to change even after they are initially published by their authors and indexed by search engines. The paper [21] describes using empirical models and a novel analytic metric of "up-to-dateness", to estimate the rate at which web search engines must re-index the web to remain current

Bharat et al paper describe the first attempt to measure the coverage and overlap of public Web search engines using a statistically sound sampling technique[39].

Website navigability measurement using metrics is reported in many papers. Yanlong Zhang et al proposed a number of metrics for website navigability measurement based on measuring website structural complexity validated these metrics against Weyuker's software complexity axioms[41]

Web metrics is a fast evolving valuable area of academic as well as commercial research. A wide ranging set of metrics has been proposed for quantifying different aspect like size[5,7,18,46,64] ,navigability[41,58],accessibility[51],design[52], usability [59].A paper by Mendes et al carried a survey literature of hypermedia and Web size metrics and classified the surveyed studies according to a proposed taxonomy[61]. 
However, many of these metrics are sometimes neither well define nor empirically validated.

\begin{tabular}{|l|l|}
\hline Sno & Name of the conference/Journal \\
\hline 1 & $\begin{array}{l}\text { International Conference on World Wide } \\
\text { Web }\end{array}$ \\
\hline 2 & $\begin{array}{l}\text { International conference on web } \\
\text { engineering }\end{array}$ \\
\hline 3 & ACM Transaction on Internet Technology \\
\hline 4 & $\begin{array}{l}\text { ACM International conference on } \\
\text { computer human Interaction(CHI) }\end{array}$ \\
\hline
\end{tabular}

Table4 :Most important web measurement journals and Conference

\section{Conclusion}

This paper has presented a systematic review of web quality evaluation methods and models . The results of the review have identified several research gaps. In particular, web quality evaluations should be performed early in the Web development should occur repeatedly throughout the design cycle, not just when the website has been completed. It also reveals that the evaluations are mainly performed in a single phase of the Web development. Quality evaluation at each phase of the Web development is critical for ensuring that the product will actually be used and be effective for its intended purpose(s).New proposals for redesign that address web quality problems as an integral part of the evaluation method are needed. Although our findings may be indicative of the field, further reviews are needed to confirm the results obtained. Future work includes the extension of this review by including other sources .

\section{References}

[1].T. C. Almind and P Ingwersen (1997), "Informetric analyses on the World Wide Web: Methodological approaches to 'webometrics"'. Journal of Documentation 53 (4): 404-426

[2] L. Björneborn and P. Ingwersen (2004), “ Towards basic framework of webometrics. Journal of the American Society for Information Science and Technology “ 55 (14): 1216-1227.

[3]M. Thelwall (2009), "Introduction to webometrics: quantitative web research for social sciences" Morgan \& Claypool.

[4] B. Schwabe and G. Rossi. (1995), "The Object-Oriented Hypermedia Design Model". Communications of the ACM.

[5]T. Bray, (1996), “ Measuring the web”, In 5th International World Wide Web Conference. Paris,France.

[6] D. Dhyani,W.K. Ng, and S.S. Bhowmick (2002), “A survey of Web metrics”, ACM Computing Surveys (34:4), pp 469-503.

[7] E. M. Mendes, N. Mosley, and S. Counsell (2001), "Web Metrics -Estimating Design and Authoring Effort", IEEE Multimedia,8(1):pp-50-57 .

[8] J.M.Kleinberg, R. Kumar, P.Raghavan, S. Rajagopalan, \&A. Tomkins.(1999), “The Web as a graph: Measurements, models, and methods" ,Lecture Notes in Computer Science(LNCS), 1627, pp-1-18. 
International Journal of Computer Science \& Engineering Survey (IJCSES) Vol.2, No.3, August 2011

[9] L.Mich ,M. Franch., L.Gaio(2003,Jan-Mar), "Evaluating and Designing the Quality of Web Sites”, IEEE Multimedia, pp.34-43.

[10] N. Di Blas, , M. P. Guermand Emilia Romagna, Carolina Orsini, , Paolo Paolini (2002), "Evaluating The Features Of Museum Websites: (The Bologna Report)", Museums and the Web 2002.

[11] L. Olsina,G. Lafuente , G.Rossi (2001), "Specifying Quality Characteristics and Attributes for Websites", Proc. Web Engineering: Managing Diversity and Complexity of Web Application Development, LNCS 2016, SpringerVerlag Eds., pp. 266 - 277, June 2001 (presented at ICSE 99 Workshop "Software Engineering over the Internet", Los Angeles, USA, 1999)

[12] O. Signore(2005,Sept 26), “A Comprehensive Model for Web Sites Quality". In Proceedings of WSE2005 -Seventh IEEE International Symposium on Web Site Evolution. Budapest Hungary. ISBN:07695-2470-2, 30-36.

[13] J. Ruiz, C. Calero, M. Piattini(2003), “A Three Dimensional Web Quality Model”. ICWE 2003, LNCS 2722, pp. 384-385.

[14]L.Olsina,. G.Rossi(2002), "Measuring Web Application Quality with WebQEM”, IEEE Multimedia Magazine, Vol. 9, 20-29.

[15] S. Mavromoustakos and A.S. Andreou(2007,Nov), "WAQE: a Web Application Quality Evaluation model” ,International Journal of web engineering and technology, Volume 3,(96-120).

[16] S. Cimino , F. Micali(2008), "Web Q-Model: a new approach to the quality", International conference on computer Human Interaction, CHI 2008, April 5 - April 10, 2008, ACM.

[17] C.R. Anderson, P. Domingos, D.S. Weld,(2001) , "Personalizing Web Sites for Mobile Users", Proc. Of the 10th Intl. WWW Conference. ACM, pp. 565-575.

[18]R. A. Botafogo,E.Rivlin,Ben Shneiderman(1992), "Structural Analysis of Hypertexts:Identifying Hierarchies and Useful Metrics", ACM Transaction on Information Systems, Vol 10, No 2, April1992, Pages 142-180.

[19] M.Deshpande, G. Karypis(2004), "Selective Markov Models for Predicting Web Page Accesses", ACM Transactions on Internet Technology, Vol. 4, No. 2, May 2004, Pages 163-184.

[20] R. Lempel, A. Soffer (2001), "Picashow: Pictorial authority search by hyperlinks on the web", In Proceedings of the 10th International World Wide Web Conference. Hong Kong.

[21] B.Brewington, G. Cybenko, (2000), "How dynamic is the web?" In Proceedings of the $9^{\text {th }}$ International World Wide Web Conference. The Netherlands.

[22] R.Ramesh Sarukkai (2000), "Link Prediction and Path Analysis Using Markov Chains" In Proceedings of the 9th international World Wide Web conference .

[23] A. Broder, R. Kumar,F. Maghoul, P. Raghavan, S. Rajagopalan, R Stata, A. Tomkins, J. Wiener.(2000), "Graph structure in the web" , In Proceedings of the 10th International World Wide Web Conference.

[24] M. Eirinaki and M. Vazirgiannis.(2007), "Web Site Personalization Based on Link Analysis and Navigational Patterns" ACM Transactions on Internet Technology, Vol. 7, No. 4, Article 21.

[25] D. Donato, L. Laura, S. Leonardi, S.Millozzi (2007), "The Web as a Graph: How Far We Are". ACM Transactions on Internet Technology, Vol. 7, No. 1, Article 4, Publication date: February 2007. 
International Journal of Computer Science \& Engineering Survey (IJCSES) Vol.2, No.3, August 2011

[26] A. Chung, T Markus ,H F. Scarselli(2006), "Computing Customized Page Ranks", ACM Transactions on Internet Technology, Vol. 6, No. 4, November 2006, Pages 381-414.

[28] Z. Bar-Yossef ,M. Gurevich(2007), “Efficient Search Engine Measurements”, In the Proceeding $16^{\text {th }}$ International World Wide Web Conference May 8-12 2007.

[29] S. Brin and L. Page(1998), "The anatomy of a large-scale hypertextual Web search engine" In 7th International World Wide Web Conference, Brisbane, Australia,April 1998.

[30] R. Lempel and S. Moran(2000), "The stochastic approach for link-structure analysis (SALSA) and the TKC effect" In 9th International World Wide Web Conference,Amsterdam, Netherlands.

[31] D. Rafiei and A. Mendelzon.( May 2000), "What is this page known for? Computing web page reputations", In $9^{\text {th }}$ International World Wide Web Conference, Amsterdam, Netherlands.

[32] Maria E. Alva O., Ana B. Martínez P., Juan M. Cueva L., T. Hernán Sagástegui Ch., and Benjamín López P(2003), "Comparison of Methods and Existing Tools for the Measurement of Usability in the Web", Published in proceeding ICWE'03 Proceedings of the 2003 international conference on Web engineering.

[33] A. Hsieh and D. Yeh (2003), "Hyperlinks Analysis of Dynamic Web Applications", ICWE 2003, LNCS 2722, pp. 349-352, 2003.

[34] Zuohua Ding Mingyue Jiang, Geguang Pu, and Jeff W. Sanders (2009), “ Modelling and Verification of Web Navigation” ICWE 2009, LNCS 5648, pp. 181-188, 2009.

[35] E. Christopoulou, J.Garofalakis, C Makris, Y.Panagis, A. Psaras-Chatzigeorgiou1, E. Sakkopoulos, A. Tsakalidis(2003), "Techniques And Metrics For Improving Website Structure” Journal of Web Engineering, Vol. 2, No.1\&2 (2003) 090-104.

[36] A. C. Soi, M. Hagenbuchner,F. Scarselli(2006), "Computing Customized Page Ranks" ACM Transactions on Internet Technology, Vol. 6, No. 4, November 2006, Pages 381-414.

[37] A.Borodin, G. Roberts, J. S. Rosenthal and P. Tsaparas,( 2001), "Finding authorities and hubs from link structures on the world wide web", In Proceedings of the 10th International World Wide Web Conference. Hong Kong.

[38] Z. Bar-Yossef ,M. Gurevich(2009), “Estimating the ImpressionRank of Web Pages”, In proceeding of $18^{\text {th }}$ International Conference of World Wide Web 2009, April 20-24, 2009, Madrid, Spain. ACM

[39] K. Bharat, A Broder,(1998), "A technique for measuring the relative size and overlap of public web search engines", In Proceedings of the Seventh International World Wide Web Conference. Australia.

[40] O. Gerstel, S. Kutten,E. S. Laber,R. Matichin ,D. Peleg,A. A. Pessoa,C. Souza(2007), “ Reducing Human Interactions in Web Directory Searches”,. ACM Transactions on Information Systems (TOIS) Volume 25 Issue 4.

[41] Y. Zhang, H. Zhu ,S. Greenwood(2004), "Website complexity metrics for measuring Navigability", In the Proceedings of fourth International conference on Quality Software(QSIC'04),IEEE.

[42] Yuming Zhou, Hareton Leung, Mnav(December 2007), "A Markov Model-Based Web Site Navigability Measure” IEEE Transactions On Software Engineering,Vol. 33, No. 12.

[43] Lorna Uden(2002), "Design Process for Web Applications” IEEE Multimedia, Volume 9 Issue 4.

[44] G.A. Di Lucca, A. R. Fasolino, P. Tramontana (2005), "Web Site Accessibility: Identifying and Fixing Accessibility Problems in Client Page Code", In Proceedings of the 2005 Seventh IEEE International Symposium on Web Site Evolution (WSE'05) .

[45] W. Chang, S. Hon(2002), “Assessing the Quality of Web-Based Applications via Navigational Structures” IEEE Multimedia, Volume 9 Issue 3. 
International Journal of Computer Science \& Engineering Survey (IJCSES) Vol.2, No.3, August 2011

[46] Calero, C., Ruiz, J., and Piattini, M. (2004), “A Web Metrics Survey Using WQM”, Proceedings ICWE04, LNCS 3140, Springer-Verlag Heidelberg, (July 2004), (2004), 147-160.

[47] R.Fayzrakhmanov, M.Göbel,W. Holzinger,B. Krüpl,A. Mager,R. Baumgartner(2010), “Modelling Web Navigation with the User in Mind". In the proceeding of W4A2010 - Communications, April 26-27, 2010.

[48] Vicki L. Hanson 2004), “The User Experience: Designs and Adaptations”, In the proceeding of W4A at WWW2004, May 18, 2004, New York, New York, USA.

[49] Sarah Horton (2006), "Designing Beneath the Surface of the Web", In Proceeding of W4A at WWW2006, 23rd-26th May 2006, Edinburgh, UK .

[50] G.Brajnik, D.Cancila, D. Nicoli, M. Pignatelli (2005), "Do text transcoders improve usability for disabled users?", In the Proceeding of W4A at WWW2005 10th May 2005, Chiba, Japan

[51]M. Vigo ,M. Arrue, G. Brajnik ,R. Lomuscio „J Abascal (2007), “Quantitative Metrics for Measuring Web Accessibility” In the Proceeding of W4A2007 - Technical Paper, May 07-08, 2007, Banff, Canada.

[52] Melody Y. Ivory,Rashmi R. Sinha, Marti A. Hearst(2001), "Empirically Validated Web Page Design Metrics" In the Proceeding of SIGCHI'01, March 31-April 4, 2001, Seattle, WA, USA. [53] Ed It. Chi, Peter Pirolli, James Pitkow (2000), "The Scent of a Site: A System for Analyzing and Predicting Information Scent, Usage, and Usability of a Web Site. actions and the Web”, In the Proceedings of CHI 2000, ACM Press, 490-497, 2001.

[54] M. H. Blackmon, P. G. Polson, M, Kitajima., \& C. Lewis( 2002), "Cognitive Walkthrough for the Web", Proceedings of CHI 2002, ACM Press, 463-470, 2002.

[55] K.Hornbæk ,E. Lai-Chong Law (2007) "Meta-Analysis of Correlations Among Usability Measures” In the proceeding of CHI 2007 , April 28-May 3, 2007 , San Jose, CA, USA.

[56] Jianhan Zhu, Jun Hong, John G. Hughes(2002), “Using Markov Models for Web Site Link Prediction" In the Proceeding of HT'02, June 11-15, 2002, College Park, Maryland, USA.

[57] Baoyao Zhou ,Jinlin Chen, Jin Shi, Hongjiang Zhang, Qiufeng Wu (2001), "Website Link Structure Evaluation and Improvement Based on User Visiting",.In the proceeding of Hypertext and Hypermedia 'HT'01' 8/01 Aarhus, Denmark.

[58] Chris Coulston,Theresa M. Vitolo(2001), “A Hypertext Metric Based on Huffman Coding”, In the Proceeding of HT'01 8/01 Aarhus, Denmark.

[59] Rui Lopes, Luís Carriço (2008), “A Model for Universal Usability on the Web”, In the Proceeding of WWW2008, April 21-25, 2008, Beijing, China.

[60] M. Y. Ivory and M. A. Hearst.(2001), “ The State of the Art in Automating Usability Evaluation of User Interfaces”, ACM Computing Surveys 33(4), 470-516.

[61] Emilia Mendes , Steve Counsell , Nile Mosley(2005) ,“Towards a taxonomy of hypermedia and web application size metrics”, In the proceeding of 5th International Conference Web Engineering, , ICWE 2005.

[62] M. Coyle , B. Smyth( 2007), “ Supporting Intelligent Web Search”, ACM Transactions on Internet Technology, Vol. 7, No. 4, Article 20, (October 2007).

[63] J.Nielsen , R.Molich (1990), “Heuristic Evaluation Of User Interfaces”,In the Proceeding of CHI'90.

[64] E. Mendes, N. Mosley, S. Counsell, (2003), "Early web size measures and effort prediction for web costimation", In the Proceedings of the 9th IEEE International Software Metrics Symposium (METRICS'2003), IEEE CS Press, Los Alamitos, CA, Sydney, pp.18-29. 